DOI: 10.20472/IAC.2017.33.010

JAMELA DWAYAT

I-Qasemi Academic College of Education- , Israel

\title{
THE CONTRIBUTION OF THE USE OF ASKING QUESTIONS STRATEGY TO IMPROVE CRITICAL THINKING AMONG STUDENTS
}

\begin{abstract}
:
The study aimed to identify the effect of using the skill of asking questions, which is one of the higher-order thinking skills, in promoting critical thinking among Arab students at a school in East Jerusalem, on the subject of reading comprehension in Arabic. The researcher has used the quasi-experimental method on a study sample of (20) students. The results showed that students performed better in the pre-exam on the realistic questions, while they faced a problem in the discretionary and analytical questions, however, after teaching them in the post- exam the responses were closer to the correctness in the discretionary questions, and the answers were correct in analytical questions.

The study recommended the need to work on the use of the skill of asking questions, because it helps the teacher and student together in developing a student's ability of thinking, answering the questions clearly, and working on implementing this skill .It also help students understand the lessons, memorizing them and retrieve them easily. In addition, there is a need for diversification in the questions and in the times of the classes, in order to enable the student to continue to listen to the teacher during the class.
\end{abstract}

\section{Keywords:}

asking questions strategy

critical thinking

Arab education

Social and cultural context

JEL Classification: 123,129 